\title{
Income Distribution and Demand-Induced Innovations
}

\author{
RETO FOELLMI and JOSEF ZWEIMÜLLER ${ }^{1}$ \\ University of Zurich
}

First version received March 2005; final version accepted January 2006 (Eds.)

\begin{abstract}
We introduce non-homothetic preferences into an innovation-based growth model and study how income and wealth inequality affect economic growth. We identify a (positive) price effect-where increasing inequality allows innovators to charge higher prices and (negative) market-size effects-with higher inequality implying smaller markets for new goods and/or a slower transition of new goods into mass markets. It turns out that price effects dominate market-size effects. We also show that a redistribution from the poor to the rich may be Pareto improving for low levels of inequality.
\end{abstract}

\section{INTRODUCTION}

The distribution of purchasing power across households can affect innovation and growth through at least two competing forces. On the one hand, a high concentration of wealth may foster innovation and growth by creating a wealthy class willing to pay high prices for new products. On the other hand, a high concentration of wealth may hinder innovation by preserving a poor majority, which could otherwise form mass markets.

Previous models of innovation and growth (Romer, 1990; Grossman and Helpman, 1992) are inadequate for studying such price and market-size effects, due to the assumption of homothetic preferences. In this paper, we introduce non-homothetic preferences into a standard R\&D-based growth model. To do this in a meaningful and tractable way, we assume that consumers expand their consumption along a hierarchy of wants. They first satisfy their basic needs before moving on to more luxurious products. Under such circumstances, only rich households will consume new goods, while poorer households can only afford less luxurious commodities.

In this framework, the distribution of income plays a crucial role in the evolution and profitability of new markets and thus for long-run growth. To see how the mechanism works, consider the dynamics of demand and profits for a firm after a successful innovation. The market for the innovation is initially small as only rich consumers purchase a new product. With growing incomes, however, the extent of the market expands and firms earn higher profits. The growth in profits is either due to the intensive margin (the same consumers are willing to pay a higher price) or due to the extensive margin (additional consumers are willing to purchase at the same price). Hence, the income distribution affects the value of an innovation in a complex way by shaping and shifting an innovator's demand curve in the growth process.

We restrict our analysis to a two-class society. Two parameters shape the distribution of income with two classes: relative incomes and relative population sizes of rich and poor. How does inequality affect the incentive to innovate? Assume there is less income inequality due to a lower relative income of rich to poor. This has two opposing effects on innovation incentives. On the one hand, such a redistribution reduces the rich households' willingness to pay the innovators' profits-as long as the new product is sold exclusively to the rich. On the other hand, such 
a redistribution makes the poor better off and enables them to afford more goods. This has a favourable effect on innovators' profits, as the market for a new product will develop into a mass market more quickly. We show that, in net terms, the former effect always dominates the latter. This is because profits become more back-loaded: the profit flow is lower early in the life cycle and higher later on. Due to discounting, the early fall in profits dominates the later increase, and the value of an innovation decreases. In sum, lower relative incomes of rich to poor have a negative effect on the incentive to innovate, which reduces growth.

Consider a more even distribution resulting from a larger population size of the rich (i.e. incomes are "less concentrated" as there are more rich with a lower income and less poor with the same income). Such a change in the distribution affects the incentive to innovate through a market-size effect and a price effect. The market-size effect has a positive impact on the profit flow, because more individuals can purchase the new good right from the start-up of the business. The price effect goes in the opposite direction. As the willingness to pay for a new product decreases with a less wealthy rich class, innovators are forced to charge lower prices. Provided the innovators' scope of price setting is large, the price effect always dominates the market-size effect, and the decreased inequality reduces growth.

The paper is organized as follows. Section 2 provides a brief review of related literature. In Section 3, we specify our crucial assumptions on consumers' preferences and discuss consumers' optimal choices in that context. Section 4 presents our assumptions on the income distribution, and Section 5 discusses technology and the firms' price-setting behaviour. Section 6 analyses the conditions for a unique balanced growth equilibrium and discusses the inequality-growth relationship as well as the welfare properties of the equilibrium. Section 7 analyses other types of equilibria. Section 8 concludes.

\section{RELATED LITERATURE}

Our paper is related to a small literature examining the relationship between the extent of economic inequality and long-run growth that works via the demand side. In a recent paper, Matsuyama (2002) discusses the interdependence between growth and distribution. In his model, the distribution of income determines market demand in sectors where learning and technical progress are possible. Growth may only benefit the rich in its initial stages but, depending on the income distribution, may ultimately trickle down to the poor. In Matsuyama (2002), growth results from learning-by-doing, which is a by-product of production in the otherwise perfect output markets. In contrast, industrial R\&D drives growth in our model, and income distribution affects growth due to its impact on innovation incentives. Murphy, Shleifer and Vishny (1989) study the role of distribution of income in the adoption of modern technologies when consumers have hierarchic preferences. While their formulation of preferences corresponds to a special case of our model, they analyse the role of income distribution in a static context. There is no scope for new firms to set prices in their model, so any effect of income distribution is transmitted via its effect on market size. Zweimüller (2000) extends the Murphy et al. (1989) model to a growth context. Just as in Murphy et al. (1989), prices and mark-ups are exogenously given and, by creating larger markets for innovative goods, less inequality has a positive impact on growth. The present paper goes beyond these studies in focusing on the double role of inequality both on the innovators' prices and on the evolution of the innovators' markets. Under our more general conditions, the relationship between inequality and growth turns out to be qualitatively different. ${ }^{2}$

2. Other models where inequality determines the level of demand for new products and where price effects are absent include Falkinger $(1990,1994)$ and Chou and Talmain (1996). For growth models that analyse the role of inequality on vertical product differentiation, see Li (1996), Glass (2001), and Zweimüller and Brunner (2005). See Flam and Helpman (1987), Matsuyama (2000), and Mitra and Trindade (2005) for papers that analyse the relationship between inequality and the structure of international trade under non-homothetic preferences.

(c) 2006 The Review of Economic Studies Limited 
Galor and Moav (2004) study a model where consumers have non-homothetic preferences over consumption and bequests. More inequality may lead to higher growth because, at early stages of development, the higher savings rate of the rich fosters physical capital accumulation. In our model, instead, the positive effect of inequality on growth works through innovations while the savings rates are constant.

Greenwood and Mukoyama (2001) address the problem of how the size distribution of income affects innovation incentives. Their focus, however, is a partial equilibrium one, in which a durable goods monopolist chooses the optimal timing of an innovation, given that consumers with unequal incomes differ in their initial purchasing dates for the product. In contrast, our model is embedded into a general-equilibrium framework, where factor prices and the aggregate growth rate are determined endogenously.

Bourguignon (1990) studies the role of demand for growth and distribution under very general assumptions on demand behaviour. He shows conditions on price and income elasticities under which growth enhances or reduces inequality. Unlike his work, our paper studies the opposite chain of causality and asks how inequality affects growth.

A further related literature is concerned with "directed" technical change (Kennedy, 1964; Acemoglu, 1998, 2002; Acemoglu and Zilibotti, 2001, and others, surveyed in Gancia and Zilibotti, 2005). These papers place emphasis on the role of relative factor prices on incentives for adopting particular technologies and the consequences of these technology choices on the distribution of income among factors of production. In contrast, the heterogeneity in our model occurs on the preference side rather than on the supply side. This allows us to study the effect of the size distribution of income on the incentives to innovate.

Other related papers study the role of demand factors on innovation and growth. Aoki and Yoshikawa (2002) build a growth model based on logistic Engel curves. Demand-induced innovations drive growth, exactly as in our model. Consumers become saturated with existing products, and innovations are thus needed to keep growth going. In contrast to our model, however, Aoki and Yoshikawa (2002) are not interested in income distribution effects and emphasize the transition process rather than the steady growth path. Young (1993) presents a model where the path of an innovator's demand does not expand in proportion to aggregate activity. Recent innovators face increasing demand because new innovations initially complement existing products, demand later decreases, however, because further innovations substitute existing products. Similar to our model, demand expectations are of central importance for innovation incentives and may give rise to multiple equilibria. Unlike our model, Young (1993) studies non-homothetic technologies (rather than preferences) and does not examine distribution effects on innovation incentives.

Voigtländer and Voth (2005) provide an interesting application of the importance of demand factors and non-homothetic preferences in a historical context. They study the role of demographic factors and redistributive measures (such as the "poor laws" in 18th- and 19th-century England) during the industrial revolution using a similar (static) theoretical set-up in which demand effects are important. They find that demand effects are essential in understanding why the industrial revolution started in England and continued in Europe while no take-off took place in other parts of the world.

\section{THE DEMAND SIDE}

\subsection{Preferences}

Consider an economy with many potentially producible differentiated products indexed by $j \in$ $[0, \infty)$. Consumers' preferences are "hierarchic" in the sense that the goods can be ranked 
according to their consumption priority. We model the hierarchy by assuming that $c(j)$ units of good $j$ yield utility $v(c(j)) \xi(j)$. This means utility is determined by a "baseline" utility, $v(\cdot)$, the same for all differentiated goods, and a weighting function, $\xi(j)$, with $\xi^{\prime}(j)<0$. This formulation yields a ranking of the various products: low- $j$ goods have a high weight (have high priority in consumption) and vice versa.

We need to restrict the functions $v(\cdot)$ and $\xi(\cdot)$. We first assume that purchasing a differentiated product is a "zero-one" decision: either a product is consumed in quantity 1 or is not consumed, $c(j) \in\{0,1\}$. This allows us to normalize the baseline utility to $v(0)=0$ and $v(1)=1$. This first assumption is primarily for tractability and analytical convenience. Second, and more importantly, we assume that the hierarchy function takes the form $\xi(j)=j^{-\gamma}$ with $\gamma \in[0,1)$. The instantaneous utility function can then be written as $u(\{c(j)\})=\int_{0}^{\infty} j^{-\gamma} c(j) d j$ and, when the first $N$ goods in the hierarchy are consumed, it takes the constant-elasticity form $u(\{c(j)\})=N^{1-\gamma} /(1-\gamma)$. This second assumption is required to generate a balanced growth path.

Consumers have an infinite time horizon. Their objective function reads ${ }^{3}$

$$
U(\tau)=\int_{\tau}^{\infty} \frac{1}{1-\sigma}\left[\int_{0}^{N(t)} j^{-\gamma} c(j, t) d j\right]^{1-\sigma} e^{-\rho(t-\tau)} d t
$$

where $\rho$ and $1 / \sigma$ denote the rate of time preference and the elasticity of inter-temporal substitution, respectively.

\subsection{Consumption choices}

Consumers are unequally endowed with labour and wealth. The inter-temporal budget constraint of a household can be written as

$$
\int_{\tau}^{\infty} \int_{0}^{N(t)} p(j, t) c(j, t) d j \cdot e^{-R(t, \tau)} d t \leq \int_{\tau}^{\infty} w(t) l \cdot e^{-R(t, \tau)} d t+V(\tau),
$$

where $N(t), p(j, t)$, and $w(t)$ denote the mass of available differentiated products, the price of variety $j$, and the wage rate, respectively, all at date $t . R(t, \tau)=\int_{\tau}^{t} r(s) d s$ is the cumulative discount factor between dates $\tau$ and $t, l$ is a household's (time-invariant) labour endowment, and $V(\tau)$ is the initial wealth level the household owns.

The household maximizes (1) subject to the budget constraint (2). Setting up the Lagrangian and defining $u(t) \equiv u(\{c(j, t)\})$, it is straightforward to obtain the first-order conditions for $c(j, t)$

$$
c(j, t)=\left\{\begin{array}{l}
1, p(j, t) \leq z(j, t) \\
0, p(j, t)>z(j, t)
\end{array}\right.
$$

where the willingness to pay $z(j, t)$ is defined by

$$
z(j, t) \equiv j^{-\gamma} \frac{e^{R(t, \tau)-\rho(t-\tau)}}{\mu} u(t)^{-\sigma}
$$

3. We assume here that the $N(t)$ goods supplied at date $t$ coincide with the first $N(t)$ goods in the consumption hierarchy. In other words, there are no "holes" in the distribution of supplied products along the hierarchy. This will be the case in the equilibria studied below, where innovators introduce always the most urgently wanted goods. 
The parameter $\mu$ denotes the Lagrangian multiplier, the marginal utility of wealth at the initial date $\tau$. (This can be translated into the more familiar "time- $t$ " marginal utility of wealth $\lambda(t)=$ $\mu e^{-R(t, \tau)+\rho(t-\tau)}$.) The two equations in (3) state that the consumer will purchase the differentiated good $j$ at date $t$, if its price $p(j, t)$ does not exceed the willingness to pay $z(j, t)$, and he will not purchase otherwise.

The consumer's willingness to pay $z(j, t)$ increases as the position of good $j$ in the hierarchy decreases (i.e. the higher the priority of good $j)$. Furthermore, $z(j, t)$ is the higher if the consumer's marginal utility of wealth $\lambda(t)=\mu e^{-R(t, \tau)+\rho(t-\tau)}$ is smaller. Rich consumers have a lower marginal utility of wealth, and their willingness to pay is higher.

\section{DISTRIBUTION}

It is assumed that all consumers have the same objective function (1) but differ in their endowments. To keep things as simple as possible, we assume there are two types of consumers, poor $\mathrm{P}$ and rich $\mathrm{R}$, with respective population sizes $\beta$ and $1-\beta$. All households derive income from their labour and from shares in profits that accrue in the monopolistic firms. We assume further that each household has the same income composition (identical labour and profit shares). Hence the ratio of the income level of the poor relative to per capita income is $\theta_{\mathrm{P}}<1$, and the corresponding ratio of the rich is $\theta_{\mathrm{R}}>1$. The income shares of poor and rich must sum up to unity, so we have $(1-\beta) \theta_{\mathrm{R}}+\beta \theta_{\mathrm{P}}=1$. Taking $\vartheta \equiv \theta_{\mathrm{P}}$ as the exogenous parameter, we have $\theta_{\mathrm{R}}=(1-\beta \vartheta) /(1-\beta)$. Hence the two parameters $\beta$ and $\vartheta$ fully characterize the income distribution.

The corresponding Lorenz curve is piecewise linear with slope $\vartheta$ for population shares between 0 and $\beta$, and slope $(1-\beta \vartheta) /(1-\beta)$ for population shares between $\beta$ and 1 . Common measures of inequality (such as the Gini coefficient, the coefficient of variation, etc.) indicate an increase in inequality as a result of a reduction in $\vartheta$ and/or an increase in $\beta$. For instance, an increase in $\vartheta$ could result from progressive taxation. A change in $\beta$ could capture a situation of a negative (positive) economic shock that affects parts of the rich (poor) population. A decrease in $\beta$ could result from making education and firm ownership more accessible to a larger fraction of the population.

\section{TECHNOLOGY AND PRICE SETTING}

\subsection{Production technology and technical progress}

The supply side of the model is standard. Labour is the only production factor, and the labour market is competitive. The market-clearing wage at date $t$ is denoted by $\tilde{w}(t)$. The goods are produced in monopolistic firms under increasing returns to scale. Before a good can be produced, the firm has to make an "innovation". This gives the firm exclusive access to the blueprint of the new good and guarantees a monopoly position. The innovation cost is modelled by a set-up cost equal to $\tilde{F}(t)$ labour units. Once this set-up cost has been incurred, the firm has access to a linear technology that requires $\tilde{b}(t)$ units of labour to produce one unit of output.

Innovations imply technical progress. We assume that the knowledge stock of this economy equals the number of known designs $N(t)$. The labour coefficients in the sector that produces differentiated goods are inversely related to the stock of knowledge. Hence we have $\tilde{F}(t)=$ $F / N(t)$, and $\tilde{b}(t)=b / N(t)$, where $F>0$ and $b>0$ are exogenous parameters. We choose the marginal production cost in the differentiated sector as the numéraire $\tilde{w}(t) \tilde{b}(t)=1$. This implies that wages grow pari passu with productivity, $\tilde{w}(t)=N(t) / b$, and the innovation cost remains constant over time as $\tilde{w}(t) \tilde{F}(t)=F / b$. 


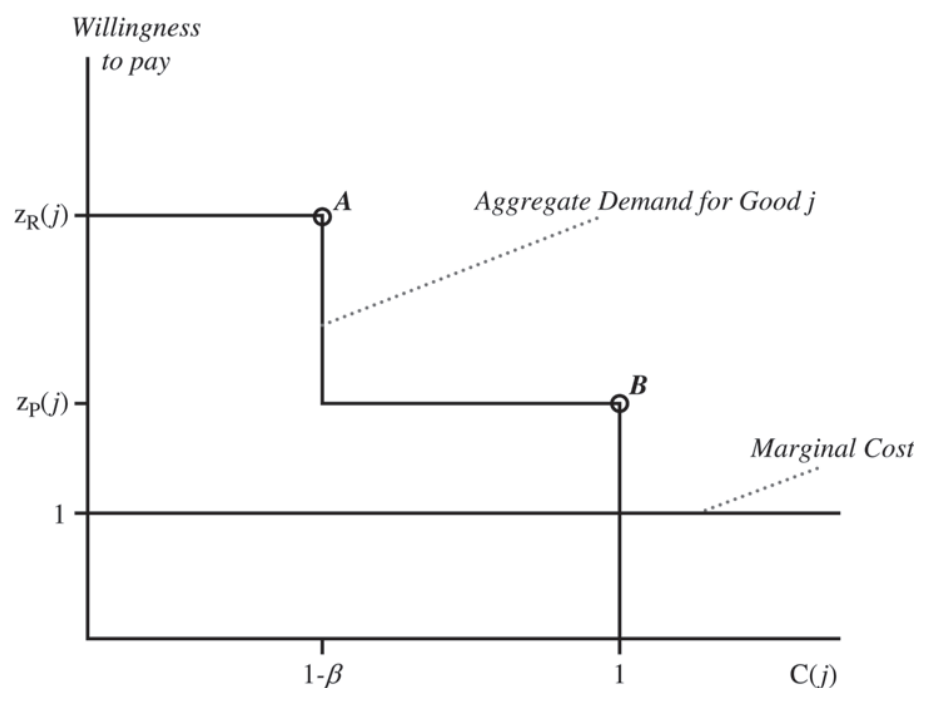

FIGURE 1

A monopolistic firm's market demand

\subsection{Prices of the differentiated goods}

Producers of differentiated products are in a monopoly position and can set prices above the marginal cost of production. In order to determine the monopoly price, we need the monopolist's demand function. Consider the demand for good $j$. (For convenience, we omit time indices in this subsection.) As consumption is a binary choice, market demand for good $j$ depends on how many consumers are willing to purchase at a given price $p(j)$. With two groups of consumers, the market-demand function is a step function (Figure 1). At prices in excess of those the rich are willing to pay, $p(j)>z_{\mathrm{R}}(j)$, demand is 0 , and the demand curve in Figure 1 coincides with the vertical axis. For prices that do not exceed the willingness of the rich to pay, but that are strictly larger than that of the poor, $p(j) \in\left(z_{\mathrm{P}}(j), z_{\mathrm{R}}(j)\right]$, market demand equals the population size of the rich $1-\beta$. Finally, for prices lower than or equal to the willingness to pay of the poor, $p(j) \leq$ $z_{\mathrm{P}}(j)$, market demand equals the size of the whole population in the economy, which is unity. ${ }^{4}$

A monopolist will either charge $z_{\mathrm{R}}(j)$ and sell only to the rich (point A in Figure 1) or charge $z_{\mathrm{P}}(j)$ and sell to the whole population (point B in Figure 1), whichever yields higher profits. The corresponding profit levels are $\left[z_{\mathrm{R}}(j)-1\right](1-\beta) \equiv \Pi_{\mathrm{R}}(j)$ (point $\left.\mathrm{A}\right)$ and $\left[z_{\mathrm{P}}(j)-1\right] \equiv \Pi_{\text {tot }}(j)$ (point B), respectively.

Suppose monopolistic firms supply $N$ products and the range of goods consumer $i$ purchases by $N_{i}$. Which firms set high prices $z_{\mathrm{R}}(j)$, and which set low prices $z_{\mathrm{P}}(j)$ ? Note first, that a situation where all $N$ firms charge $z_{\mathrm{R}}(j)$ and sell only to the rich cannot be an equilibrium. If the poor would not buy any differentiated products at all, their willingness to pay for goods $j \rightarrow 0$ would become infinitely large. Hence there must be some $j>0$ such that $\Pi_{\text {tot }}(j) \geq \Pi_{\mathrm{R}}(j)$, or equivalently, $z_{\mathrm{P}}(j)-z_{\mathrm{R}}(j)(1-\beta) \geq \beta$, which implies that $z_{\mathrm{P}}(j) / z_{\mathrm{R}}(j)>1-\beta$. Note further that a situation where all firms charge $z_{\mathrm{P}}(j)$ also cannot be an equilibrium. In that case we would have $N_{\mathrm{P}}=N_{\mathrm{R}}$, so that poor and rich would spend the same amount on consumption goods. Since

4. Obviously, there are more such kinks, if there are more types of consumers, and we have a smooth demand function in the case of continuous distribution. In any case, under the indivisibility assumption, the shape of the demand function reflects the distribution of the consumers' willingness to pay. 
the rich would not exhaust their budget constraint, their marginal utility of wealth would be 0 , and $z_{\mathrm{R}}(j)$ equals infinity. It is then profitable for a monopolist to deviate and sell only to the rich. This leads us to the following:

Proposition 1. Firms set the prices for all goods $j \in\left[0, N_{\mathrm{P}}\right]$ in such a way that $p(j)=$ $z_{\mathrm{P}}(j)$, and we have $p(j)=z_{\mathrm{R}}(j)$ for all $j \in\left(N_{\mathrm{P}}, N_{\mathrm{R}}\right]$, where $0<N_{\mathrm{P}}<N_{\mathrm{R}} \leq N$.

Hence Proposition 1 implies that the prices of the differentiated products are

$$
p(j, t)= \begin{cases}z_{\mathrm{P}}(j, t), & j \in\left[0, N_{\mathrm{P}}(t)\right] \\ z_{\mathrm{R}}(j, t), & j \in\left(N_{\mathrm{P}}(t), N_{\mathrm{R}}(t)\right] .\end{cases}
$$

Proposition 1 implies that the poor consume all goods $j \in\left[0, N_{\mathrm{P}}\right]$, and the rich consume all goods $j \in\left[0, N_{\mathrm{R}}\right]$ where $0<N_{\mathrm{P}}<N_{\mathrm{R}} \leq N$. This implies that "consumption follows the hierarchy" in the sense that consumer $i$ purchases only the first $N_{i}$ products in the hierarchy, and no product $j>N_{i}$. The poor purchase low- $j$ goods, that is, goods that satisfy their most urgent wants. The rich purchase not only those necessities, but can also afford more luxurious goods. These observations lead us to

Proposition 2. The equilibrium is characterized by one of two regimes. In the first regime, $N_{\mathrm{P}}(t)<N_{\mathrm{R}}(t)=N(t)$, the rich purchase all products that firms can produce. In the second regime, $N_{\mathrm{P}}(t)<N_{\mathrm{R}}(t)<N(t)$, the rich purchase only a subset of all producible goods.

Proposition 2 has important implications for the characteristics of the balanced growth path. We will see below that, along this path, the ratios $N_{\mathrm{P}}(t) / N(t)<1$ and $N_{\mathrm{R}}(t) / N(t) \leq 1$ are constant over time. When $N_{\mathrm{R}}(t) / N(t)=1$ and rich consumers purchase all producible goods, the most recent innovator sells the new product to the rich right away and to the poor later on. We will call this situation the "regime IS" ("innovate and sell"). When $N_{\mathrm{R}}(t) / N(t)<1$, rich consumers do not purchase all producible goods. The most recent innovator has to wait for a while until there is positive demand for his new good. We will refer to this case as the "regime IW" ("innovate and wait"). We will discuss the IS case in some detail in the next section and will refer briefly to regime IW in Section 7.

Regime IW may appear to be a strange outcome to some readers. After all, there are always some very rich people able to pay a very high price for any new product in the real world. Such an equilibrium outcome is therefore simply an artefact of the two-class assumption (and which can arise only when the two classes are sufficiently similar). It is nevertheless worthwhile to consider regime IW since a situation where innovators incur costs in order to capture a new market may in fact be more than a theoretical possibility. ${ }^{5}$ Such an outcome may occur when the innovation costs are low and the prospective (future) market is sufficiently profitable.

\section{BALANCED GROWTH: REGIME IS}

\subsection{The allocation of resources across sectors}

The economy's resources consist of the stock of knowledge $N(t)$ and the homogeneous labour each household in the economy supplies. At any date $t, N(t)$ is predetermined but affects current productivities $\tilde{b}(t)$ and $\tilde{F}(t)$. Total labour supply is normalized to unity. Since innovation is costly,

5. As an example, The Economist (6 April, 2000) notes in an article on "patent wars": "Biotech companies, which often have nothing to sell for years, find their value residing solely in their intellectual property". 
a part of the economy's resources are employed in an R\&D sector that develops blueprints for new products. The remaining labour force is employed in the production of final output. The allocation of labour resources across sectors is endogenously determined. We denote by $L_{Y}$ the number of production workers and by $L_{\mathrm{I}}$ the number of research workers. The demand for production labour is given by $L_{\mathrm{Y}}(t)=\int_{0}^{N(t)}[b / N(t)]\left[\beta c_{\mathrm{P}}(j, t)+(1-\beta) c_{\mathrm{R}}(j, t)\right] d j$. As the rich consume all feasible products and the poor only a subset $n(t) \equiv N_{\mathrm{P}}(t) / N(t)$, this simplifies to $L_{\mathrm{Y}}(t)=$ $b[\beta n(t)+(1-\beta)]$. The demand for research workers depends on $\dot{N}(t)$, the level of innovation activities at date $t$. As introducing a new product requires $F / N(t)$ labour units, the demand for research workers is $L_{\mathrm{I}}=F \dot{N}(t) / N(t)=F g(t)$.

A perfect labour market ensures that the labour supply is fully employed at each date, so $1=L_{\mathrm{Y}}+L_{\mathrm{I}}$. Using the above expressions for $L_{\mathrm{I}}$ and $L_{\mathrm{Y}}$, the economy's resource constraint can be written as

$$
1=b[\beta n(t)+(1-\beta)]+F g(t) .
$$

The dynamic analysis below focuses on a balanced growth path, along which the allocation of labour across the two sectors remains constant over time. From equation (5) it is obvious that a balanced growth path is only possible if $n(t)=n$ and $g(t)=g$ do not change over time.

\subsection{Prices and interest rate along the balanced growth path}

How do the prices of some product $j$ evolve along the balanced growth path? Denote the date when the good is introduced by $\tau$. At that point in time, the innovating firm charges the price $p(j, \tau)=z_{\mathrm{R}}(j, \tau)$, and the rich start purchasing. As their income grows, rich households are willing to pay more for any given product, and the innovator can raise his price. The calculation of the rate of change in the price is straightforward from the definition of $z_{\mathrm{R}}(j, t)$. Recall that $z_{\mathrm{R}}(j, t)=j^{-\gamma} e^{R(t, \tau)-\rho(t-\tau)} u_{\mathrm{R}}(t)^{-\sigma} / \mu_{\mathrm{R}}$ and that-as households consume "along the hierarchy" $-u_{\mathrm{R}}(t)=N(t)^{1-\gamma} /(1-\gamma)$. Using this in the expression for $z_{\mathrm{R}}(j, t)$, taking logs and the derivative with respect to time $t$ yields

$$
\frac{\dot{p}(j, t)}{p(j, t)}=\frac{\dot{z}_{\mathrm{R}}(j, t)}{z_{\mathrm{R}}(j, t)}=r(t)-\rho-\sigma(1-\gamma) \frac{\dot{N}(t)}{N(t)} .
$$

Prices grow at that rate until firms find it optimal to attract the poor as additional customers. At that date, firms cut prices from what the rich are willing to pay $z_{\mathrm{R}}(j, s)$ to what the poor can pay $z_{\mathrm{P}}(j, s)$. After date $s$, the rate of change in $z_{\mathrm{P}}(j, s)$ determines price changes. The willingness to pay of the poor is $z_{\mathrm{P}}(j, t)=j^{-\gamma} e^{R(t, \tau)-\rho(t-\tau)} u_{\mathrm{P}}(t)^{-\sigma} / \mu_{\mathrm{P}}$ where $u_{\mathrm{P}}(t)=[n \cdot N(t)]^{1-\gamma} /(1-\gamma)$. Since $n$ is constant along the balanced growth path, $\dot{z}_{\mathrm{P}}(j, t) / z_{\mathrm{P}}(j, t)$ yields exactly the same expression as equation (6).

We can make a slightly different thought experiment and look at the evolution of the price $p\left(N_{i}(t), t\right)$. This is the price for the good with least priority (i.e. the most luxurious good) that consumer $i$ purchases. Setting $j=N_{\mathrm{R}}(t)=N(t)$ in the above expression for $z_{\mathrm{R}}(j, t)$ and $j=$ $N_{\mathrm{P}}(t)=n \cdot N(t)$ in the expression for $z_{\mathrm{P}}(j, t)$, taking logs and the derivative with respect to time $t$ yields (in each case)

$$
\frac{\dot{p}\left(N_{i}(t), t\right)}{p\left(N_{i}(t), t\right)}=r(t)-\rho-(\gamma+\sigma(1-\gamma)) \frac{\dot{N}(t)}{N(t)} .
$$

Along a balanced growth path, the menu of consumed goods increases at the same rate as $N(t)$ for both types of consumers. This rate is constant and given by $g$. Furthermore, the price of the most recently developed good $N(t)$ has to stay constant over time, otherwise the resources devoted to 


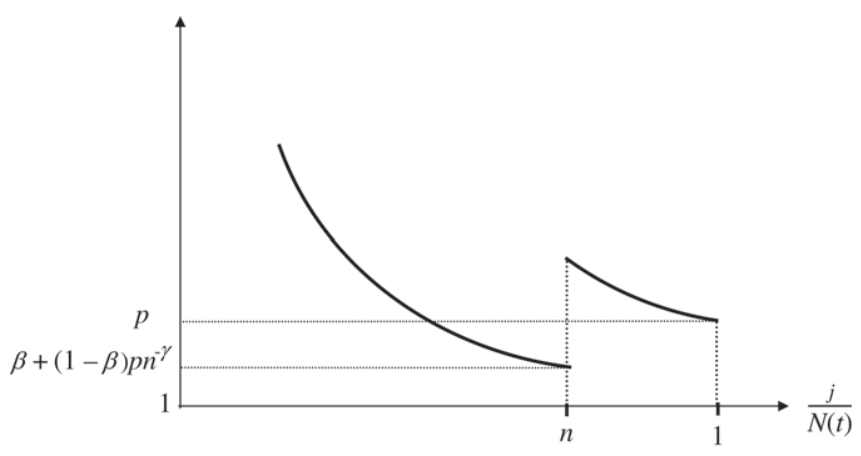

FIGURE 2

Mark-up structure along the balanced growth path

R\&D $L_{\mathrm{I}}$ would change (see the next subsection). Using $\dot{p}(N(t), t)=\dot{p}(n \cdot N(t), t)=0$ we can solve the above equation for the interest rate

$$
r(t)=\rho+g(\gamma+\sigma(1-\gamma))
$$

which, unsurprisingly, is also constant along the balanced growth path. Equation (7) in our model is the equivalent to the familiar Euler equation in the standard growth model and is identical to it in the absence of a consumption hierarchy $\gamma=0$. Note further that, in the special case where $\sigma=0$, the hierarchy parameter $\gamma$ tells us how an increase in the range of consumed goods affects the utility flow, just like the elasticity of marginal utility in the standard model.

Reinserting the interest rate (7) into equation (6), we see that $\dot{p}(j, t) / p(j, t)=g \gamma$, hence the price of a particular good increases at a constant rate. However, the price of a particular relative position in the consumption hierarchy, $j / N(t)$, is independent of $t$. In other words, the distribution of prices stays constant along the balanced growth path.

The endogenous variables $g, p(N(t), t)$, and $p\left(N_{\mathrm{P}}(t), t\right)$ determine the distribution of prices. For further use, it will be convenient to focus on the price of the most recently innovated product and define $p \equiv p(N(t), t)=z_{\mathrm{R}}(N(t), t)$. Furthermore, it will be expedient to express the price $p\left(N_{\mathrm{P}}(t), t\right)$ in terms of the endogenous variables $p$ and $n$. We know from Proposition 1 that the firm supplying good $N_{\mathrm{P}}$ is indifferent between selling to the whole customer base and selling only to the rich, as $N_{\mathrm{P}}$ satisfies the arbitrage condition $z_{\mathrm{P}}\left(N_{\mathrm{P}}\right)-1=\left[z_{\mathrm{R}}\left(N_{\mathrm{P}}\right)-1\right](1-\beta)$. (For simplicity, we omit time indices.) We know further from equation (3), that $z_{\mathrm{R}}\left(N_{\mathrm{P}}\right)=n^{-\gamma} z_{\mathrm{R}}(N)$. Using this and the definition $z_{\mathrm{R}}(N)=p$, we can solve the arbitrage condition for the price of $\operatorname{good} N_{\mathrm{P}}$

$$
p\left(N_{\mathrm{P}}(t), t\right)=z_{\mathrm{P}}\left(N_{\mathrm{P}}(t), t\right)=\beta+(1-\beta) n^{-\gamma} p .
$$

In sum, the price of a new good starts out with price $p$, increases at rate $g \gamma$, drops to $\beta+(1-\beta) n^{-\gamma} p$ once firms find it optimal to attract the poor as customers as well, and then increases at rate $g \gamma$ thereafter. Figure 2 depicts the equilibrium prices as a function of $j / N$.

Two comments on the evolution of prices are in order. First, the relative position of a particular good $j$ in the hierarchy, $j / N$, decreases in the growth process. In this sense, a good that was previously a luxury good, now becomes a necessity. This is reflected in increasing willingnesses to pay and rising mark-ups (and rising prices because marginal costs are normalized to unity) for 
this product. ${ }^{6}$ Second, the discontinuous evolution of prices with a discrete jump when the poor start to purchase, is due to our assumption of two groups of consumers. With many groups, there would be many small changes in prices in order to attract additional customers instead of one big change.

\subsection{The innovation process}

Up to now we have taken a continuous introduction of new products (and corresponding increases in productivity) for granted. We now look at the incentives to conduct R\&D and introduce new products.

We assume that there is free entry into the R\&D sector, and the equilibrium is a situation of zero profits in which the cost and the value of an innovation are exactly balanced. The cost of an innovation is given by $F / b$ whereas the value of an innovation remains to be determined. Note first that innovation efforts will be targeted towards those goods for which consumers are willing to pay most. Hence the innovation process will follow the consumption hierarchy.

To calculate the value of an innovation, we need to know the profit flow following the introduction of a new product. A successful firm has initial demand $1-\beta$ up until the date when prices are cut and also the poor are attracted as customers. From that date onwards, all consumers purchase, and demand equals unity. Let $\Delta$ denote the time interval during which only the rich purchase a new product. $\Delta$ must satisfy $N_{\mathrm{P}}(t+\Delta)=N(t)$. Along a balanced growth path, $N_{\mathrm{P}}$ grows at the constant rate $g$, and we can write $N_{\mathrm{P}}(t) e^{g \Delta}=N(t)$. Taking logs and solving for $\Delta$ yields

$$
\Delta=-\ln \left[N_{\mathrm{P}}(t) / N(t)\right] / g=-(\ln n) / g .
$$

Note that $\Delta>0$ because $n<1$ holds. Obviously, the duration $\Delta$ during which an innovator sells only to the rich is long if (i) the poor are very poor (meaning that the fraction of goods the poor can afford $n$ is small) and (ii) the growth rate $g$ is low.

Recalling the evolution of prices and noting that we have normalized the marginal production cost to unity, the profit flow equals $(1-\beta)\left(p e^{g \gamma(s-t)}-1\right)$ at dates $s \in[t, t+\Delta)$ (when the firm sells only to the rich) and equals $\left[\beta+(1-\beta) n^{-\gamma} p\right] e^{g \gamma(s-t-\Delta)}-1$ at dates $s \geq t+\Delta$ (when all households purchase the good). The value of an innovation equals the value of this profit flow, discounted at rate $r$. Calculating this value and setting it equal to the costs of an innovation yields the zero-profit condition of the innovation sector

$$
\frac{F}{b}=(1-\beta)\left(\frac{p}{r-g \gamma}-\frac{1}{r}\right)+\beta n^{r / g}\left(\frac{1}{r-g \gamma}-\frac{1}{r}\right) .
$$

\subsection{Solving for the equilibrium growth rate}

We can now solve for the balanced growth equilibrium. We use Proposition 1 to rewrite the budget constraints (2) of poor and rich consumers, respectively, as

$$
\begin{aligned}
& w l_{\mathrm{P}}+(r-g) \frac{V_{t \mathrm{P}}}{N_{t}}=\left[\beta n+(1-\beta) p n^{1-\gamma}\right] \frac{1}{1-\gamma}, \text { and } \\
& w l_{\mathrm{R}}+(r-g) \frac{V_{t \mathrm{R}}}{N_{t}}=\left[\beta n+(1-\beta) p n^{1-\gamma}\right] \frac{1}{1-\gamma}+p \frac{1-n^{1-\gamma}}{1-\gamma} .
\end{aligned}
$$

6. We do not allow for any changes in the market structure over the product cycle so that prices grow without bound. An easy way to cope with this problem would be to introduce finite patent protection and marginal cost pricing once patents have expired. As long as patents expire after the poor have started to purchase the product, the relationship between inequality and growth will remain (qualitatively) unchanged. 
Dividing the former equation by the latter and making use of our assumption on the endowment distribution $l_{\mathrm{P}} / l_{\mathrm{R}}=V_{t \mathrm{P}} / V_{t \mathrm{R}}=\theta_{\mathrm{P}} / \theta_{\mathrm{R}}=\vartheta(1-\beta) /(1-\vartheta \beta)$ yields an equation that can be solved for $p$

$$
p=\varphi(n)=\frac{(1-\vartheta) \beta}{1-\beta} \frac{n}{\vartheta-n^{1-\gamma}}, \text { with } \varphi^{\prime}(n)>0 .
$$

The intuition for the positive relationship between $p$ and $n$ is straightforward: For a given degree of inequality (as represented by the exogenous parameters $\beta$ and $\vartheta$ ), a situation where the poor want to purchase a larger range of the differentiated products ( $n$ is higher) goes hand in hand with a situation where the rich are willing to pay a higher price for the most recent innovator's product ( $p$ is higher).

Equation (9) demonstrates how this restricts the relevant range of $p$ and $n$. Note that $n<1$ and $p>1$. Equation (9) implies that $p$ reaches infinity at $n=\vartheta^{1 /(1-\gamma)}<1$. Moreover, we see that a critical value of $n$ exists, call it $m$, such that $\varphi(m)=1$. Hence the relevant ranges for the endogenous variables $p$ and $n$ are $p \in[1, \infty)$ and $n \in\left[m, \vartheta^{1 /(1-\gamma)}\right)$.

To determine the growth rate, we are now left with two equations in the two unknowns $g$ and $n$. The first equation is (5). We obtain the second equation from rewriting the R\&D equilibrium condition (8) using equations (7) to replace $r$ and (9) to replace $p$

$$
\frac{F}{b}=\frac{(1-\beta) \varphi(n)+\beta n^{\rho / g+(\gamma+\sigma(1-\gamma))}}{\rho+g \sigma(1-\gamma)}-\frac{1-\beta+\beta n^{\rho / g+(\gamma+\sigma(1-\gamma))}}{\rho+g(\gamma+\sigma(1-\gamma))} .
$$

No closed-form solution for the equilibrium growth rate $g$, and the consumption share of the poor $n$ exists.

We now discuss the conditions under which a general equilibrium exists. We will concentrate in the present section on the case when the hierarchy parameter $\gamma$ is small, and therefore regime IW can be ruled out. We will abandon this assumption in Section 7 and discuss the properties of the balanced growth equilibrium in regime IW.

\section{Assumption: flat hierarchy $\quad \gamma \leq \sigma F \rho /(\sigma F \rho+b)$.}

We will show that the general equilibrium, with a "flat hierarchy", is unique, and innovators never have a waiting time. To characterize the general equilibrium, it is convenient to draw the two conditions (10) and (5) in the $(g, n)$ space. In Figure 3, we will refer to the former equation as the ZP curve ("zero profit") and to the latter equation as the RC curve ("resource constraint").

Let us next consider the position and slope of the RC and ZP curves. Equation (5) is linear in both $g$ and $n$ and implies a negative relationship between these two variables. More resources for innovation and growth (a higher $g$ ) are only feasible in regime IS at the expense of lower consumption by the poor (a lower $n$ ). The ZP curve is more complex. We show in Appendix A that the ZP curve crosses the $n$-axis to the right of $m$, where $m$ is given by $\varphi(m)=1$. When $g \rightarrow \infty$ the ZP curve becomes a vertical line at $n \rightarrow \vartheta^{1 /(1-\gamma)}$. This can be seen from (9) and (10). For $0<g<\infty$, the slope of the ZP curve is generally not clear a priori. However, when the hierarchy is flat, $\gamma \leq \sigma F \rho /(\sigma F \rho+b)$, a larger $g$ is always associated with an increase in $n$, that is, the ZP curve is monotonically increasing (see Appendix A). The ambiguity in the general case arises because the effect of $g$ on the value of an innovation can be positive or negative (whereas the effect of $n$ is always positive). A higher $g$ not only raises the interest rate, but also increases mark-ups and flow profits as well. The former effect is the familiar discounting effect, which decreases the value of an innovation. The latter effect arises due to hierarchic preferences. It increases the value of an innovation and is the stronger the larger $\gamma$ is. ${ }^{7}$ When the hierarchy is sufficiently flat, the former effect dominates the latter, and the ZP

7. Recall from our previous discussion that prices increase at rate $g \gamma$. Hence, with a higher $g$, mark-ups and profits increase at a higher rate. 


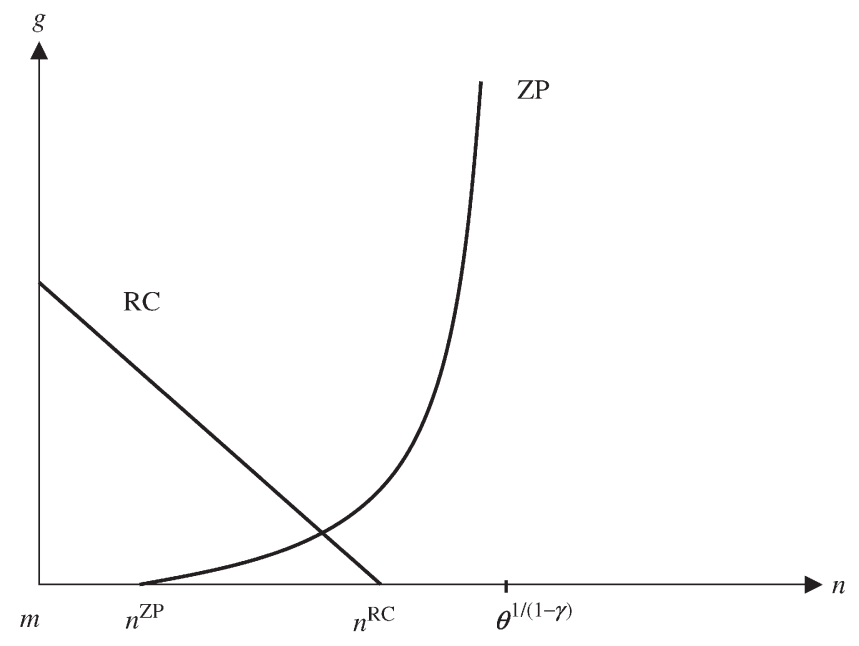

FIGURE 3

Aggregate equilibrium. The ZP and the RC curve

curve is monotonically increasing. The intuition for the positive relation between $g$ and $n$ is then straightforward: a larger $n$ (which increases the value of an innovation) has to be offset by an increase in $g$ (which then decreases this value) to make sure that the zero-profit condition (10) is satisfied.

We are now ready to state the following:

Proposition 3. Suppose the hierarchy is flat, $\gamma \leq \sigma F \rho /(\sigma F \rho+b)$ and denote the horizontal intercepts of the $\mathrm{ZP}$ and $\mathrm{RC}$ curve as $n^{\mathrm{ZP}}=\varphi^{-1}(1+F \rho /[(1-\beta) b])$ and $n^{\mathrm{RC}}=[1 / b-$ $(1-\beta)] / \beta$. (a) If $n^{\mathrm{ZP}}<n^{\mathrm{RC}}$, a unique general equilibrium with a positive growth rate $g>0$ exists. (b) If $n^{\mathrm{ZP}} \geq n^{\mathrm{RC}}$, the unique equilibrium is stagnation $g=0$.

\section{Proof. See Appendix A. \|}

\subsection{The effect of inequality on growth}

Having established conditions for existence and uniqueness of a general equilibrium, we now turn to the question of our central interest: how does the extent of inequality affect long-run growth? The following proposition gives an answer to this question.

Proposition 4. Suppose the hierarchy is flat, $\gamma \leq \sigma F \rho /(\sigma F \rho+b)$, and a unique equilibrium with a positive growth rate exists. (a) An increase in relative incomes of the poor $\vartheta$ decreases the growth rate $g$ and decreases the consumption share of the poor $n$. (b) An increase in the group share of the poor $\beta$, holding $\theta_{\mathrm{P}}=\vartheta$ constant, increases $g$ and has an ambiguous effect on $n$.

\section{Proof. See Appendix B. ॥}

The proposition states that more income inequality increases innovation and growth. (Recall that an increase in the distribution parameter $\vartheta$ implies less inequality, whereas an increase in the population share of the poor $\beta$, holding $\theta_{\mathrm{P}}=\vartheta$ constant, implies higher inequality.) The 
results of the above proposition can be checked graphically. Let us first look at what happens when the parameter $\vartheta$ increases. Equation (5) shows that this increase does not affect the RC curve. However, $\vartheta$ enters equation (10) via $\varphi(n)$, affecting the ZP curve. When $\vartheta$ increases, $\varphi(n)$ decreases, see equation (9). From inspection of (10) we see that, holding $g$ constant, any reduction in $\varphi(n)$ must be offset by a corresponding increase in $n$, otherwise (10) would be violated. Hence the $\mathrm{ZP}$ curve must shift to the right. The new equilibrium has a lower growth rate and a higher consumption share of the poor. Consider next the impact of an increase in the parameter $\beta$. Provided $\vartheta$ remains constant, this increases relative incomes of the rich but leaves the poor unaffected. Such a change affects both the RC curve and the ZP curve. From (5), any increase in $\beta$ must be offset by a corresponding increase in $n$. Hence the RC curve shifts to the right. Moreover, the ZP curve shifts to the left. An increase in $\beta$ decreases the R.H.S. of (10) directly and increases it indirectly because $\varphi(n)$ increases in $\beta$. Appendix B shows that the direct effect dominates. To offset this, $n$ has to decrease.

The above proposition states that a higher income ratio of rich to poor (through a lower $\vartheta$ ) as well as a higher concentration of income among the rich (through a higher $\beta$ ) both increase growth. What is the intuition behind these results? Let us first consider the impact of a higher income ratio of rich to poor. The intuition is easiest to see from the resource constraint (5). While the rich still consume all goods after the redistribution, the lower income of the poor translates into lower consumption, that is, a lower fraction of affordable goods. In other words, the rich cannot increase their consumption, so making them richer lets them spend more for the same goods but does not require additional resources. The poor have a lower income and have to decrease their consumption that releases resources that can be employed in the R\&D sector, which increases growth.

A different way to look at this result is by considering the impact of higher relative income of rich to poor on the value of an innovation (the R.H.S. of the zero-profit condition (10)). A higher relative income of rich to poor has two effects. The first effect is a price effect. The rich have a higher willingness to pay, which increases the prices of new goods, whereas the poor have a lower willingness to pay, which decreases the prices of old goods. In other words, a new innovator starts out with higher prices (as long as the product is sold exclusively to the rich) and ends up with lower prices (when the product has become a mass product sold to the whole population). This shifts profits from the future towards the present which, due to discounting, raises the value of an innovation. The second effect is a (dynamic) market-size effect, a slower transition from exclusive markets to mass markets. However, this has only a second-order effect on profits because the expansion of market size coincides with lower prices. (In fact, at the switching date, the firm is indifferent between selling only to the rich and selling to the entire population.) Taken together, the former price effect always dominates the market-size effect, so that a higher income ratio of rich to poor unambiguously increases the rate of growth.

Let us next consider the effect of a larger population share of the poor on the growth rate. This implies that incomes are more concentrated. (There are more poor with the same income and fewer rich with a higher income.) To gain intuition let us again look at the resource constraint (5) first. A higher income concentration means that fewer households consume all goods, and more households consume only part of the goods. Provided the consumption level of the poor does not increase (a reasonable benchmark since their endowment remains unchanged), less production labour is needed to satisfy aggregate consumption demand. Resources are released for the R\&D sector, allowing higher growth.

Alternatively, let us look at the effect of a larger population share of the poor on the value of an innovation. As long as the income of the poor remains unchanged, prices, market sizes, and profits for mass consumption goods $j \in\left[0, N_{\mathrm{P}}\right]$ remain unchanged as well. However, exclusive firms $j \in\left(N_{\mathrm{P}}, N\right]$ now make strictly higher profits than before. When incomes are concentrated 
among fewer rich, exclusive markets are smaller but generate higher prices. How does this translate into profits? For exclusive goods very close to mass consumption (for $j \rightarrow N_{\mathrm{P}}$ ) firms become indifferent between selling to all and selling only to rich households. In other words, profits approach the mass consumption profit for good $N_{\mathrm{P}}$ and do not vary strongly with income concentration. Income concentration makes a difference for exclusive goods farther away from mass consumption $j>>N_{\mathrm{P}}$, however. Along the hierarchy, prices and profits for exclusive goods fall with $j$, but they fall less strongly with a higher concentration of income. In other words, the most recent innovator makes higher initial profits when entering the market, whereas profits become increasingly independent of income concentration at later stages of the life cycle. ${ }^{8}$

\subsection{Redistribution and welfare}

With more inequality fostering innovation and growth, it is interesting to ask whether there is a Pareto-improving redistribution such that the poor might even gain from a regressive transfer. Surprisingly, the answer is yes.

The welfare analysis turns out to be quite simple. Because there is only one state variable, $N(t)$, and because the technology is linear in $N(t)$, the economy jumps immediately into the new steady state after an exogenous shock. We continue to focus on regime IS below and consider the impact of higher inequality due to a reduction in $\vartheta$ on welfare. We know from Proposition 4 above that such a change increases the growth rate. Immediately after the redistribution, the rich group enjoys the same consumption flow, but this flow grows at a higher rate. Hence, unsurprisingly, the welfare level of the rich is higher.

How is the welfare level of the poor affected? Obviously, there are two effects. The static effect reduces welfare. The lower income forces the poor to consume less. The dynamic effect increases welfare as the consumption flow grows at a larger rate. Let us calculate the utility level of the poor. As $n$ and $g$ are constant in steady state, the welfare level of a poor agent can be calculated using (1)

$$
U_{\mathrm{P}}(\tau)=\frac{1}{1-\sigma}\left[\frac{N(\tau)^{1-\gamma}}{1-\gamma}\right]^{1-\sigma} \frac{n^{(1-\gamma)(1-\sigma)}}{\rho-g(1-\gamma)(1-\sigma)} .
$$

(The formula of a rich agent takes the same form with $n=1$.) To answer our question take the derivative of $U_{\mathrm{P}}(\tau)$ with respect to the relative income of the poor $\vartheta$

$$
\frac{d U_{\mathrm{P}}(\tau)}{d \vartheta}=B n^{-\sigma(1-\gamma)-\gamma}\left[1-\frac{b \beta}{F} \frac{n}{\rho-g(1-\gamma)(1-\sigma)}\right] \frac{d n}{d \vartheta},
$$

where $B$ is a positive constant. Note that we used the resource constraint (5) to calculate $d g / d n=$ $-b \beta / F$. We know from Proposition 4 that the share of goods consumed by the poor increases with their income, $d n / d \vartheta>0$. Hence, the poor gain from a regressive transfer when the term in brackets in (11) is negative. If the income of the poor is low ( $n$ close to 0 ), the poor will always suffer from a decrease in $\vartheta$. However, when the poor are relatively wealthy ( $n$ is close to unity), a Pareto-improving transfer may exist.

8. More precisely, we must have indifference of firms between exclusive and mass markets for the critical good $N_{\mathrm{P}}$, that is, $(1-\beta)\left[z_{\mathrm{R}}\left(N_{\mathrm{P}}\right)-1\right]=z_{\mathrm{P}}\left(N_{\mathrm{P}}\right)-1$. From Section 6.2 we know that $z_{\mathrm{R}}(j)=z_{\mathrm{R}}\left(N_{\mathrm{P}}\right) \cdot\left(j / N_{\mathrm{P}}\right)^{-\gamma}$. Hence profits for exclusive goods $j \in\left(N_{\mathrm{P}}, N\right]$ can be written as $(1-\beta)\left[z_{\mathrm{R}}(j)-1\right]=\left[z_{\mathrm{P}}\left(N_{\mathrm{P}}\right)-1\right]\left(j / N_{\mathrm{P}}\right)^{-\gamma}+(1-\beta)\left[\left(j / N_{\mathrm{P}}\right)^{-\gamma}-1\right]$. Assume (as in the text) that $z_{\mathrm{P}}\left(N_{\mathrm{P}}\right)$ is unaffected by the change in $\beta$. The latter expression shows that for exclusive goods $\left(j>N_{\mathrm{P}}\right)$ profits increase in $\beta$, and the rise in profits is bigger the higher $j$ is. 
Proposition 5. A Pareto-improving transfer may exist if $\rho F<b \beta+(1-b)(1-\gamma)(1-\sigma)$.

Proof. For perfect equality, $\vartheta \rightarrow 1, n$ approaches 1 and the growth rate equals $g=(1-b)$ $/ F$ using the resource constraint (5). Inserting these values into (11) gives us the condition stated in the proposition.

When $\vartheta$ decreases, the poor lose today but gain through higher growth rates in the future. Such an outcome is more likely if households are patient, that is, $\rho$ is low, so that the dynamic gains dominate the static losses. Note also that a larger group share of the poor $\beta$ makes the condition in Proposition 6 easier to hold. With $\beta$ large, a decrease in $n$ releases more resources for the research sector, hence the growth rate increases more strongly.

The reason for this striking result lies in the fact that the rich make the new innovations possible by paying the high prices of the innovative goods. This increases profits and triggers entry in the research sector. While the poor suffer today, the increase in growth may be large enough to outweigh the present loss in consumption.

\section{BALANCED GROWTH: REGIME IW}

We abandon the flat-hierarchy assumption in this section and explore the case where the hierarchy is steep, so that the hierarchy parameter $\gamma>\sigma F \rho /(\sigma F \rho+b)$. The nature of the general equilibrium may change in such a situation. In particular, the ZP curve may become non-monotonic, giving rise to multiple equilibria, and the regime IW-where innovators have to wait until their new good is demanded-may become an equilibrium. (In such an equilibrium, innovators anticipate that there will be demand in the future and discount the resulting profit flow. By incurring research effort early, they pre-empt potential competitors and conquer a monopoly position on a new market.)

Let us consider the equilibrium in regime IW where new firms have a waiting time until the new product is demanded in positive amounts. In regime IW, conditions (5), (9), and (10) change to

$$
\begin{aligned}
& 1=g F+b n[(1-\beta) / m+\beta], \\
& \frac{1-\vartheta}{(1-\beta) \vartheta}=\frac{1-m^{1-\gamma}}{\beta m+(1-\beta) m^{1-\gamma}},
\end{aligned}
$$

and

$$
\frac{F}{b}=\left(1-\beta+\beta m^{r / g}\right)\left[\frac{1}{r-g \gamma}-\frac{1}{r}\right]\left(\frac{n}{m}\right)^{r / g},
$$

where $r=\rho+g(\gamma+\sigma(1-\gamma))$ by equation (7). These are three equations in the three unknowns $g, m$, and $n$. Here $m \equiv N_{\mathrm{P}}(t) / N_{\mathrm{R}}(t)$ denotes the relative consumption levels between poor and rich consumers. Note that $m$ is determined directly from equation (13) and depends only on the hierarchy parameter $\gamma$ and the distribution parameters $\beta$ and $\vartheta$. It does not depend on technological factors and is independent of the growth rate. ${ }^{9}$ This allows us to characterize the equilibrium graphically using equations (12) and (14).

9. Note that we have already calculated $m$ in our discussion of equation (9) above. There we have defined $m$ as the limit case in regime IS, such that $\varphi(m)=1$. In other words, we are at the limit $n=m=N_{\mathrm{P}} / N_{\mathrm{R}}$ when the rich are willing to pay exactly the marginal production cost and in regime IW the willingness to pay is even lower. In regime IW, $m$ is constant, whereas $n$ falls short of $m$. Hence, a smooth transition between regimes IS and IW exists. 

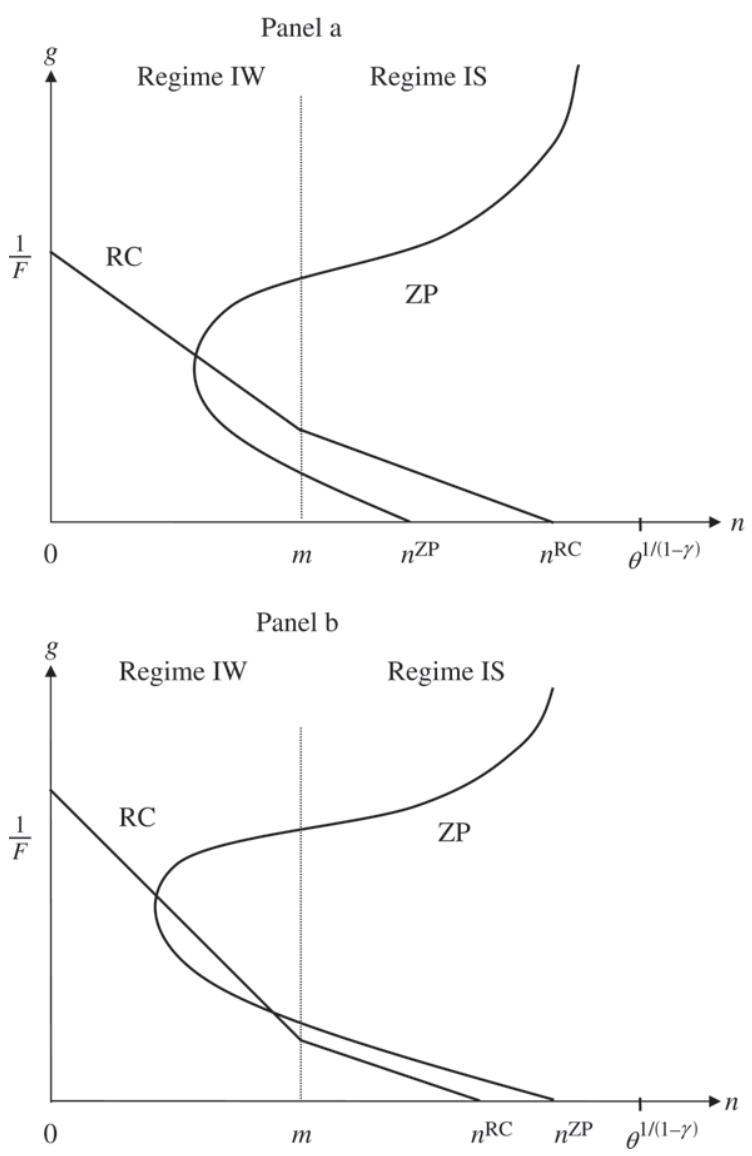

FIGURE 4

Steep hierarchy and multiple equilibria

Panel (a) of Figure 4 depicts an equilibrium in regime IW with steep hierarchy. In that case the ZP curve bends backwards. The slope is negative when $g$ is low and becomes positive for higher values of $g$ such that the ZP curve bends back in regime IS. Again, once $n \rightarrow$ $\vartheta^{1 /(1-\gamma)}>m$ the ZP curve becomes a vertical line. A positive growth equilibrium in regime IW is more likely when $F$ is very small, so the ZP curve is satisfied for low values of $n$. In that case, the (low) costs of innovation activities pay off even when the rich consumers' willingness to pay is initially low, and innovators earn positive profits only in the future. This is intuitive, in such a case innovators are willing to incur research costs even if they have to wait.

Panel (b) of Figure 4 shows a situation where there are multiple equilibria. There is a stagnation equilibrium at $n=n^{\mathrm{RC}}$, and two growth equilibria, drawn in regime IW. ${ }^{10}$ The reason why multiple equilibria occur lies in a strong demand effect when hierarchy is steep. An innovating firm's demand depends on the economy-wide growth rate. If innovators expect high growth, they

10. The way panel (b) in Figure 4 is drawn is exemplary. By means of simulations, it turns out that the bad equilibrium is always stagnation, whereas positive growth equilibria may be either both in regime IW, both in regime IS, or one (with the lower growth rate) in IS and the other (with the higher growth rate) in IW. 
anticipate that their market will quickly develop into a mass market, with fast-growing prices and profits. Hence optimistic growth expectations support an equilibrium with a high incentive to innovate. If innovators expect low growth, profit expectations and the resulting incentive to innovate are correspondingly low. Hence pessimistic expectations sustain a low level of innovative activities and vice versa.

The presence of steep hierarchy leaves the impact of income inequality on growth qualitatively unchanged for most cases. The situation is similar, though slightly more complicated than in regime IS. More inequality does not necessarily imply that fewer resources are needed to satisfy aggregate consumption demand. While the poor consume fewer, the rich now consume more goods. Graphically, an increase in the relative income of the poor $\vartheta$ shifts the ZP curve to the right, but the RC curve is also affected (in regime IW an increase in $\vartheta$ raises $m$ and shifts the RC curve to the right). However, simulations render the result that the overall change is a reduced growth rate when $\vartheta$ increases or $\beta$ decreases.

Proposition 6. Assume the hierarchy is steep, $\gamma>\sigma F \rho /(\sigma F \rho+b)$, and a unique equilibrium with a positive growth rate exists. (a) An increase in relative incomes of the poor $\vartheta$ decreases the growth rate $g$, decreases the consumption share of the poor $n$, and increases the consumption share of the rich $n / m$. (b) An increase in the group share of the poor $\beta$, holding $\theta_{\mathrm{P}}=\vartheta$ constant, increases the consumption share of the rich $n / m$, decreases the growth rate $g$, and has an ambiguous effect on $n$.

The intuition why higher inequality also tends to increase growth in regime IW is similar to that for regime IS. Higher inequality through a higher income ratio of rich to poor increases the value of an innovation because positive profits accrue earlier in the product cycle (the waiting time for the wealthier rich is shorter) whereas the transition to a mass market occurs later. The former effect is first order whereas the latter effect is second order, so the result is higher growth. A larger population share of the rich also leads to an increase in the value of an innovation. There are fewer rich who start to purchase new goods earlier and who pay higher prices for exclusive goods. The resulting increase in the value of an innovation stimulates innovative activities and long-run growth. It is worth noting, however, that the growth-enhancing effect of inequality is less strong in regime IW than in regime IS. In the latter, an increase in inequality did not have an impact on consumption by the rich (they were consuming all goods anyway). In regime IW, however, the consumption of the rich increases requiring resources and dampening the positive growth effect of higher inequality.

It is also interesting to study welfare consequences of redistributing income from the poor to the rich. Since growth increases as a result of higher inequality, the rich gain from such a redistribution. It can be shown that there are parameter constellations where also the poor gain. In other words, a Pareto-improving redistribution is also possible in regime IW though less likely (i.e. the parameter space when this occurs is smaller). The reason is that growth effects are weaker because, and unlike in regime IS, the rich will increase the number of goods they consume. Therefore, fewer resources are shifted from production to the R\&D sector.

\section{DISCUSSION}

We have presented an endogenous growth model where consumers have non-homothetic preferences and where the distribution of income plays a central role for innovation and growth. We have shown that when price effects dominate market-size effects, higher inequality is favourable for growth. Our model is based on simplifying assumptions, both on the form of preferences and on the distribution of income. So let us briefly discuss the importance of these assumptions. 
We have made two important assumptions on preferences. First, we have assumed a consumption hierarchy, which weights subutilities with a power function. The power form of the weighting function $i^{-\gamma}$ is essential for balanced growth. It implies that demand functions and monopoly prices only depend on the position of good $j$ relative to the total number of available goods $N(t)$ (rather than its absolute position) in the hierarchy. As a result, the maximized static utilities can be expressed as a function of the flow of total consumption expenditures, the function taking the constant-elasticity form with parameter $\gamma$. In other words, in inter-temporal problems with a continuum of indivisible goods, assuming additive separability and weighting by a power function is the analogue of a constant relative risk aversion-felicity function in the one-sector growth model. Second, we have assumed goods are indivisible. Giving up the indivisibility assumption potentially changes the nature of the inequality-growth relationship. More precisely, the way in which continuous consumption affects this relationship will depend on the functional form of the $v(\cdot)$-function. For instance, to attain a situation where poor consumers cannot afford certain goods, non-negativity constraints have to bind. (This requires a subutility function with the property $v^{\prime}(0)<\infty$.) Furthermore, the functional form of the subutility $v(\cdot)$ determines the shape of individual demand functions. If these demand functions are non-linear in income, there are additional distributional effects, which do not show up under indivisibility. While allowing for continuous consumption is beyond the scope of this paper, it may be an interesting direction for future research.

Concerning the distribution of income and wealth we have confined our analysis to a twoclass society. With two classes, the basic mechanisms can be made precise while keeping the analysis simple and tractable. An open question is whether our results carry over to more general distributions of income and wealth. Suppose there are three income classes, and consider a redistribution from the middle class to the rich. In the new equilibrium, the rich still consume all goods whereas middle-class households now consume less. This saves resources, which can be employed in R\&D to increase growth. More generally, as long as more inequality is the outcome of transfers towards the richest households, our basic result remains valid. When more inequality results from a higher income of the middle class at the expense of the poor, there is no direct effect on the demand for production labour as the increase in consumption of the middle class is offset by a reduction in consumption of the poor. However, the increased consumption of the middle class tends to shift innovators' profits towards the present, increasing the value of an innovation and enhancing growth.

A further important assumption of our analysis is that consumers can only purchase differentiated products supplied by monopolistic firms while no appropriate substitutes for these goods exist. Introducing a non-innovative sector that supplies such substitutable goods is potentially important because it limits the innovative firms' scope for price setting. ${ }^{11}$ In that case, redistributing income from poor to rich households stimulates demand in the non-innovative sectors. Rather than paying higher prices for the same innovative goods, the rich purchase more non-innovative goods and thus utilize more resources, which otherwise were employed in R\&D. With sufficient substitutability, price effects could become too weak to stimulate innovation and growth.

11. The working paper version of this paper, Foellmi and Zweimüller (2004), works out the case of intermediate substitutability when consumers have Cobb-Douglas preferences over the composite of the differentiated goods and a perfectly divisible non-innovative good. In an equilibrium, where the rich purchase all differentiated products while the poor can only afford part of them, an increase in the relative income of rich to poor is still growth enhancing. However, increases in income concentration (by increasing the population share of the poor) do not necessarily enhance growth. The reason is that price effects are weaker as consumers increasingly purchase non-innovative goods when the innovative products become too expensive. Price effects may thus be too weak to outweigh market-size effects. 


\section{APPENDIX A}

Proof of Proposition 3. We have to establish the slope and horizontal intercept of the ZP curve. In integral notation, we can rewrite the value of an innovation $B$, that is, the R.H.S. of equation (10), as

$$
\begin{aligned}
B(g, n)= & \int_{t}^{t+\Delta}(1-\beta)\left(\varphi(n) e^{g \gamma(s-t)}-1\right) e^{-r(s-t)} d s \\
& +\int_{t+\Delta}^{\infty}\left(\left[\beta+(1-\beta) n^{-\gamma} \varphi(n)\right] e^{g \gamma(s-t-\Delta)}-1\right) e^{-r(s-t)} d s
\end{aligned}
$$

We first calculate the horizontal intercept of the ZP curve, $n^{\mathrm{ZP}}$. We note that $g \rightarrow 0$ implies an infinitely long waiting time $\Delta \rightarrow \infty$. Evaluating $B(g, n)$ at $g=0$, setting the resulting expression equal to the costs of innovation $F / b$, and solving for $\varphi\left(n^{\mathrm{ZP}}\right)$ yields

$$
\varphi\left(n^{\mathrm{ZP}}\right)=1+\frac{F \rho}{(1-\beta) b}>1 .
$$

Since $\varphi(n)$ increases in $n$, we also note that $n^{\mathrm{ZP}}>m=\varphi^{-1}(1)$.

To calculate the slope of the ZP curve, it suffices to check the signs of the partial derivatives of $B(g, n)$ with respect to the endogenous variables $g$ and $n$. We see that $\partial B / \partial n>0$. The derivative with respect to $g$, noting that $\Pi_{R}(N(t+\Delta))=\Pi_{\text {tot }}(N(t+\Delta))$, is given by

$$
\begin{aligned}
\frac{\partial B}{\partial g}= & \int_{t}^{t+\Delta}(1-\beta)\left[(\sigma(1-\gamma)+\gamma)-\sigma(1-\gamma) \varphi(n) e^{g \gamma(s-t)}\right] e^{-r(s-t)}(s-t) d s \\
& +\int_{t+\Delta}^{\infty}\left[(\sigma(1-\gamma)+\gamma)-\sigma(1-\gamma)\left(\beta+(1-\beta) n^{-\gamma} \varphi(n)\right) e^{g \gamma(s-t-\Delta)}\right] e^{-r(s-t)}(s-t) d s .
\end{aligned}
$$

We first state a sufficient condition for the second integral above to be negative. If $\gamma \leq \sigma F \rho /(\sigma F \rho+b)$, the following holds $n^{-\gamma} \varphi(n)>\varphi(n) \geq \varphi\left(n^{\mathrm{ZP}}\right)=1+F \rho /[(1-\beta) b] \geq 1+\gamma /[\sigma(1-\gamma)(1-\beta)]$ where $\varphi(n) \geq \varphi\left(n^{\mathrm{ZP}}\right)$ is true when the curve has a positive slope. The condition on $\varphi(n)$ implies that the term in brackets of the second integral is nonpositive. The same condition also implies the first integral to be negative: we directly see that $\sigma(1-\gamma)+\gamma-\sigma(1-\gamma)$ $\varphi(n) e^{g \gamma(s-t)} \leq 0$ if $\varphi(n) \geq 1+\gamma /[\sigma(1-\gamma)]$, which is a weaker condition. \|

\section{APPENDIX B}

Proof of Proposition 4. It suffices to ask how the equilibrium curves defined by (5) and (10) are affected. From the static equilibrium condition (9) we see that $\partial \varphi / \partial \theta<0$ and $\partial \varphi / \partial \beta>0$. A rise in $\theta$ does not affect the RC curve, since this parameter does not appear. A rise in $\beta$, however, implies that fewer resources are needed, the RC curve shifts up. To discuss the shifts of the ZP curve, note that $\Pi_{\mathrm{tot}}(j)=\left[\beta n^{\gamma}+(1-\beta) \varphi(n)\right](j / N)^{-\gamma}-1$, and $\Pi_{\mathrm{R}}(j)=\left[\varphi(n)(j / N)^{-\gamma}-1\right]$ $(1-\beta)=\varphi(n)(1-\beta)(j / N)^{-\gamma}+\beta$. Using the formula for $\varphi(n)$ from equation (9) we get the expression $\varphi(n)(1-\beta)=$ $\beta(1-\theta) n /\left(\theta-n^{1-\gamma}\right)$. Hence, $\varphi(n)(1-\beta)$ falls in $\theta$ and increases in $\beta$. With $n$ fixed, we directly attain the result that $\partial \Pi_{\text {tot }}(j) / \partial \theta<0, \partial \Pi_{\mathrm{R}}(j) / \partial \theta<0$ and $\partial \Pi_{\text {tot }}(j) / \partial \beta>0, \partial \Pi_{\text {tot }}(j) / \partial \beta>0$. Consequently, the ZP curve shifts to the right when $\theta$ increases, and it shifts to the left when $\beta$ increases.

Acknowledgements. We thank Fabrizio Zilibotti, the editor, and two anonymous referees for valuable suggestions. We are grateful to Daron Acemoglu, Antoine d'Autumne, Josef Falkinger, Lars Ljungqvist, Kiminori Matsuyama, Manuel Oechslin, Gilles Saint-Paul, and seminar participants at MIT, Northwestern University, Toulouse, Mannheim, NBER Summer Institute, German Economic Association Conference in Innsbruck, the RES Conference in Warwick, and the ESEM Meeting in Venice for helpful comments. Reto Foellmi acknowledges support from the SNF Research Grant No. PA001-105068.

\section{REFERENCES}

ACEMOGLU, D. (1998), "Why Do New Technologies Complement Skills? Directed Technical Change and Wage Inequality”, Quarterly Journal of Economics, 113, 1055-1089.

ACEMOGLU, D. (2002), "Directed Technical Change", Review of Economic Studies, 69, 781-810.

ACEMOGLU, D. and ZILIBOTTI, F. (2001), "Productivity Differences", Quarterly Journal of Economics, 116, 563-606.

AOKI, M. and YOSHIKAWA, H. (2002), "Demand Saturation-Creation and Economic Growth", Journal of Economic Behavior and Organization, 48, 127-154. 
BOURGUIGNON, F. (1990), "Growth and Inequality in the Dual Model of Development: The Role of Demand Factors", Review of Economic Studies, 57, 215-228.

CHOU, CH.-F. and TALMAIN, G. (1996), "Redistribution and Growth: Pareto Improvements", Journal of Economic Growth, 1, 505-523.

FALKINGER, J. (1990), "On Growth Along a Hierarchy of Wants", Metroeconomica, 41, 209-223.

FALKINGER, J. (1994), "An Engelian Model of Growth and Innovation With Hierarchic Demand and Unequal Incomes", Ricerche Economiche, 48, 123-139.

FLAM, H. and HELPMAN, E. (1987), "Vertical Product Differentiation and North-South Trade", American Economic Review, 76, 810-822.

FOELLMI, R. and ZWEIMÜLLER, J. (2004), "Heterogenous Mark-ups, Demand Composition, and the InequalityGrowth Relation" (Mimeo, University of Zurich).

GALOR, O. and MOAV, O. (2004), "From Physical to Human Capital Accumulation: Inequality and the Process of Development", Review of Economic Studies, 71, 1001-1026.

GANCIA, G. and ZILIBOTTI, F. (2005), "Horizontal Innovation in the Theory of Growth and Development", in $\mathrm{Ph}$. Aghion and S. Durlauf (eds.) Handbook of Economic Growth (Amsterdam: North-Holland).

GLASS, A. J. (2001), "Price Discrimination and Quality Improvement", Canadian Journal of Economics, 34, 549-569.

GREENWOOD, J. and MUKOYAMA, T. (2001), "The Effect of Income Distribution on the Timing of New Product Introductions" (Mimeo, University of Rochester).

GROSSMAN, G. M. and HELPMAN, E. (1992) Innovation and Growth in the Global Economy (Cambridge, MA: MIT Press).

KENNEDY, CH. (1964), "Induced Bias in Innovation and the Theory of Distribution”, Economic Journal, 74, $541-547$.

LI, CH.-W. (1996), "Inequality and Growth: A Schumpeterian Perspective" (Mimeo, University of Glasgow).

MATSUYAMA, K. (2000), "A Ricardian Model with a Continuum of Goods Under Nonhomothetic Preferences: Demand Complementarities, Income Distribution and North-South Trade", Journal of Political Economy, 108, 1093-1120.

MATSUYAMA, K. (2002), "The Rise of Mass Consumption Societies”, Journal of Political Economy, 110, 1035-1070.

MITRA, D. and TRINDADE, V. (2005), "Inequality and Trade", Canadian Journal of Economics, 38, 1253-1271.

MURPHY, K. M., SHLEIFER, A. and VISHNY, R. (1989), "Income Distribution, Market Size, and Industrialization”, Quarterly Journal of Economics, 104, 537-564.

ROMER, P. (1990), "Endogenous Technological Change", Journal of Political Economy, 98, S71-S102.

VOIGTLÄNDER, N. and VOTH, H.-J. (2005), "Why England? Demand, Growth and Inequality During the Industrial Revolution" (Mimeo, Universitat Pompeu Fabra, Barcelona).

YOUNG, A. (1993), "Substitution and Complementarity in Endogenous Innovation", Quarterly Journal of Economics, 108, 775-807.

ZWEIMÜLLER, J. (2000), “Schumpeterian Entrepreneurs Meet Engel's Law: The Impact of Inequality on InnovationDriven Growth", Journal of Economic Growth, 5, 185-206.

ZWEIMÜLLER, J. and BRUNNER, J. K. (2005), "Innovation and Growth with Rich and Poor Consumers", Metroeconomica, 56, 233-262. 